\title{
A Commitment to the Vision of Our Journal
}

\author{
Charles N. Cornell, MD
}

Received: 29 March 2015/Accepted: 10 April 2015/Published online: 7 May 2015

(C) Hospital for Special Surgery 2015

Welcome to Volume 11 Issue 2 of the HSS Journal. The winter of 2015 will be remembered as particularly harsh with lots of cold and snow. However, the staff of the HSS Journal ${ }^{\mathbb{R}}$ was undeterred by the weather in their efforts to continue to improve the journal as an unbiased resource for clinicians committed to musculoskeletal medicine and surgery. A retreat was held in December and attended by the hospital leadership, the editorial board and our publishers from Springer. The growth of the journal's readership was reviewed. We renewed our commitment to keeping the journal multidisciplinary, as free of bias as possible and an efficient resource for clinicians from all musculoskeletal disciplines.

This issue once again provides a wide variety of articles including new research as well as pertinent reviews. With this issue, we present a new feature. Going forward, we will be providing Evidenced Based Reviews in Orthopedics of specific topics in orthopedic surgery that are drawn from the monthly journal club run by our resident staff. The journal club typically reviews one or two articles of significant interest. The articles are presented by the resident staff and a thor- ough review of the literature focusing on the evidentiary contribution of the selected manuscript is performed. The presentations are notable for their quality and scholarship. I am grateful that these valuable efforts will now be shared with our readership.

I hope you find the material in this issue of value. Your commentary will always be welcomed. I hope you will continue to consider the HSS Journal as resource for your ongoing study as well as a user-friendly place for publication of your work.

\section{Disclosures}

Conflict of Interest: Charles N. Cornell, MD has declared that he has no conflict of interest.

Human/Animal Rights: This article does not contain any studies with human or animal subjects performed by the any of the authors.

Informed Consent: N/A

Required Author Forms Disclosure forms provided by the authors are available with the online version of this article. 